\title{
A produção do espaço em Portalegre/RN
}

\section{Boanerges de Freitas Barreto Filhoa,*}

a Universidade do Estado do Rio Grande do Norte, Rua Almino Afonso, 478, Mossoró, Brasil, 59610-210

\section{Informações}

Recebido 12 Maio 2021

Manuscrito revisado recebido

25 agosto 2021

Aceito 09 Setembro 2021

Palavras-chave

Produção do espaço

Relações sociais

Relações econômicas

Produto-produtor

\section{Resumo}

A cidade é o lócus onde as forças capitalistas se manifestam por modificações das paisagens naturais pela infraestrutura construída por interessados na produção do espaço. O objetivo deste trabalho é analisar a produção do espaço em Portalegre/RN. Para tanto, recorreu-se à pesquisa de campo, interpretando a realidade a partir da coleta de dados primários, com obtidas no Google Earth Pro, entrevistas com moradores e pesquisa documental e bibliográfica. Os espaços incorporados ao processo urbano na cidade decorreram da estruturação de equipamentos turísticos construídos e/ou incentivados pelo Poder Público, pela construção de bairros populares nas franjas da cidade a partir da ação estatal e pela disposição de alguns proprietários de áreas nos arredores da cidade em loteálas. Conclui-se que a produção do espaço na cidade é resultado da intervenção estatal, diretamente pela construção de equipamentos públicos e de casas populares e/ou indiretamente, atendendo aos anseios para ampliar o Perímetro Urbano para a abertura de loteamentos.

\section{Environmental services and disservices associated with urban and periurban agriculture in the city of São Paulo}

\section{Article info \\ Received 12 May 2021 \\ Received in revised form 25 August 2021 \\ Accepted 09 September 2021}

\section{Keywords}

Space production

Social relations

Economic relations

Product-producer

\begin{abstract}
The city is the lócus where capitalist forces are manifested by modifying natural landscapes by infrastructure construction by those interested in space production. The objective of this work is to analyze the production of space in Portalegre/RN. For this purpose, field research was used, interpreting the reality from the collection of primary data, obtained from Google Earth Pro, interviews with residents and document and bibliographic research. The spaces incorporated into the urban process in the city resulted from the structuring of tourist facilities and/or encouraged by the Government, the construction of popular neighborhoods on the city edges by state action and the provision of some owners of areas on the outbound of the city. It is concluded that the production of space in the city is the result of state intervention, directly through the construction of public facilities and popular houses and/or indirectly, meeting the desire to expand the Urban Perimeter for the opening of subdivisions
\end{abstract}

\section{Servicios y perjuicios ambientales asociados a la agricultura urbana y periurbana en la ciudad de São Paulo}

\section{Información}

Recibido 12 Mayo 2021

Manuscrito revisado recibido 25 Agosto 2021

Aceptado 09 Septiembre 2021

\section{Palabras clave}

Produccion del espacio

Relaciones sociales

Relaciones económicas

Producto-productor

\section{Resumen}

La ciudad es el lócus donde las fuerzas capitalistas se manifiestan modificando los paisajes naturales a través de la infraestructura construida por los interesados en la producción del espacio. El objetivo de este trabajo es analizar la producción del espacio en Portalegre/RN. Para ello, se utilizó la investigación de campo, interpretando la realidad a partir de la recolección de datos primarios, obtenidos de Google Earth Pro, entrevistas a residentes e investigación documental y bibliográfica. Los espacios incorporados al proceso urbanístico de la ciudad resultaron de la estructuración de equipamientos turísticos construidos y/o impulsados por el Poder Público, la construcción de barrios populares en las periferias de la ciudad a través de la acción estatal y la disposición de algunos propietarios de áreas de los alrededores de la ciudad. Se concluye que la producción del espacio en la ciudad es el resultado de la intervención estatal, directamente a través de la construcción de equipamientos públicos y viviendas populares y/o indirectamente, atendiendo al deseo de ampliar el Perímetro Urbano para la producción de lotes.

\footnotetext{
* Autor correspondente em: Universidade do Estado do Rio Grande do Norte, Rua Almino Afonso, 478, Mossoró, Brasil, 59610-210.
}

E-mail: boanerges.sms@hotmail.com (Boanerges F. B. Filho, ORCID 0000-0003-1777-3520) 


\section{Introdução}

A produção do espaço é o resultado deliberado da ação humana sobre o meio natural, consequentemente, impondo-Ihes, quase sempre, alterações drásticas. Neste sentido, afirma-se que as intervenções humanas no meio natural estão na origem da constituição de povoados, vilas, cidades, visando satisfazer as necessidades mais imediatas dos habitantes, destacando-se as de moradia, de proteção para os grupos e indivíduos, realização de celebrações religiosas, para lazer e diversões e, ao longo do tempo, cada vez mais, por motivações econômicas.

Por ser uma ação humana deliberada é que Lefebvre (2013) apresenta a concepção de produção social do espaço, uma vez que o espaço urbano reflete as contradições entre o capital e o trabalho. Assim, a contradição fundamental capital-trabalho se materializa na produção do espaço urbano, cujos fragmentos (parcelas do espaço) se constituem em mercadorias e passam a ser controlados e comercializados em favor dos capitalistas.

Neste sentido, observa-se um movimento de homogeneização que submete o espaço a condição de mercadoria, consequentemente, podendo ser parcelado, controlado e comercializado. Por outro lado operam forças econômicas e sociais que diferenciam os espaços, hierarquizando-os. Logo, os controladores (proprietários) de parcelas de espaços nobres em cidades modernas, atrativas e dinâmicas economicamente se distinguem das massas do precariado urbano empurradas para a periferia e compelidas a viver distantes da cidade organizada (LEFEBVRE, 2013; HARVEY, 2014).

Não obstante, muitas cidades possam parecer espaços caóticos, duvidando-se da existência de normas e/ou planejamento por parte das autoridades constituídas, tem-se a vigência, especialmente a partir do Modo de Produção Capitalista (MPC), da preservação da propriedade privada, aspecto essencial e que contempla os interesses das classes mais abastadas da sociedade, assegurando-Ihes o controle das áreas mais valorizadas. Ademais, a fixação de normas, que devem ser seguidas pelos habitantes, visa resguardar que as distintas funcionalidades no interior das, e entre as cidades sejam viabilizadas.

Com o MPC são potenciadas as necessidades para que o Estado cumpra o papel precípuo de resguardar as propriedades privadas, bem como são demandadas intervenções para solucionar os problemas de infraestrutura, evidenciando-se que o "espaço urbano capitalista" é o "resultado de ações acumuladas no tempo" (CORRÊA, 2000, p. 11).

Neste sentido, o capital produz e reproduz o espaço que, por sua vez, serve, simultaneamente, de mediador de relações sociais e econômicas, bem como, constituindo-se em instrumento para viabilização do processo de acumulação (LEFEBVRE, 2013).

Embora a produção do espaço se torne mais visível nas metrópoles do mundo, observa-se que o processo de "[...] fragmentação do espaço como mercadoria" se espraiou e alcança os lugares mais longínquos, incluindo cidades pequenas. Tornamse visíveis processos de expansões urbanas e surgimento de loteamentos nos arredores de cidades pequenas, especialmente "[...] naquelas com algum atrativo turístico ou produtivo (inclusive agropecuário)." (ALVES, 2019, p. 553).

Procurando contribuir com o debate e tendo como base empírica a cidade de Portalegre/RN, reconhecendo-se a complexidade e a natureza multidimensional da realidade (materialidade), analisa-se a produção do espaço na referida cidade. Leva-se em consideração que o "[...] espaço urbano apresenta um sentido profundo, pois se revela condição, meio e produto da ação humana - pelo uso - ao longo do tempo" (CARLOS, 2007, p. 11).

Procedeu-se a caracterização da cidade, utilizando-se fontes bibliográficas, documentais e trabalho de campo, com a observação direta e realização de entrevistas com os moradores mais antigos, bem como utilização do Google Earth Pro para captura de imagens das áreas de expansão recente da cidade. As entrevistas ${ }^{1}$ foram realizadas no ano de 2016, adotando-se a técnica de "bola de

1 Adotou-se a realização de entrevistas não estruturadas, em função da necessária flexibilidade para o levantamento e checagem de informações. 
neve"2, com abordagens feitas nas visitas de campo para identificação dos moradores mais antigos das áreas, procedendo-se a checagem de informações com três fontes distintas em cada área.

A opção adotada foi o estudo de caso, que serve para aprofundar a análise de uma determinada realidade a partir do cenário e de um contexto específico, contribuindo para a compreensão de fenômenos sociais complexos (DENZIN; HAGUETTE, 1987; TRIVIÑOS, 1987; YIN, 2001).

Considera-se a produção do espaço um fenômeno social complexo, tendo em conta que não se constitui apenas em fenômeno geográfico ou econômico, exigindo-se olhares e saberes transdisciplinares, demandando esforço para evidenciação de que na escala espacial estudada, a cidade de Portalegre/RN, também se materializam intervenções que, respeitadas as particularidades existentes, compatibilizam-se com os movimentos verificáveis em cidades de maior porte.

\section{Produção do espaço em cidades pequenas: breves considerações}

De início, é importante ressaltar que o espaço não é "[...] um 'produto' qualquer, coisa ou objeto, mas um conjunto de relações" (LEFEBVRE, 2013). Isso porque:

\section{"Enquanto produto, por interação ou retroação, o espaço intervém na própria produção: organização do trabalho produtivo, transportes, fluxo das matérias-primas e das energias, redes de distribuição dos produtos. À sua maneira produtivo e produtor, o espaço entra nas relações de produção e nas forças produtivas (mal ou bem organizado). Seu conceito não pode, portanto, isolar-se e permanecer estático. Ele se dialetiza: produto-produtor, suporte das relações econômicas e sociais (LEFEBVRE, 2013, p. 125)."}

Essa dialetização do espaço requer o reconhecimento de sua atuação como mediador de "[...] relações econômicas e sociais" (LEFEBVRE,

2 Segundo Baldin e Munhoz (2012), a técnica bola de neve é uma forma de amostra não probabilística em que os participantes iniciais indicam mais participantes até que o objetivo das entrevistas seja alcançado.
2013, p. 131). Assim: "O modo de produção organiza, produz - ao mesmo tempo que certas relações sociais - o seu espaço (e o seu tempo). É assim que ele se realiza" (LEFEBVRE, 2013, p. 128).

Conforme Amaral (2009), o fenômeno da urbanização desempenhou um papel importante no desenvolvimento do capitalismo e na acumulação de capital, pois as cidades passaram a concentrar as condições gerais de produção, tais como, força de trabalho e capital:

\begin{abstract}
"O modo de produção capitalista reconfigurou a cidade, tornando-a centro econômico e financeiro, além de político-administrativo. Modificou relações sociais e produziu profundas transformações espaciais. Induziu uma revolução na atividade agrícola e alterações no sistema de propriedade e de organização do trabalho rural (AMARAL, 2009, p. 12)."
\end{abstract}

O espaço, pós Revolução Industrial, passou a ser organizado (utilizado) a partir da lógica capitalista e até mesmo nas cidades afastadas, geograficamente, das megalópoles que se encontram no topo da hierarquia urbana, posto que são, cada vez mais, integradas para viabilização do processo de acumulação capitalista em escala ampliada, ainda que a contribuição de cada cidade pequena seja muito modesta no contexto geral.

A centralidade das cidades na sociedade capitalista é inegável. É o lócus privilegiado em que as forças capitalistas se manifestam da forma mais vigorosa, pois viabilizou e continua expandindo os horizontes dos mercados. À medida que a acumulação de capital se intensifica novas estruturas geográficas são forjadas e modificam incessantemente as relações espaciais. É a expansão do capitalismo em busca de espaços mais lucrativos que viabiliza a ocorrência de novas organizações espaciais, consequentemente, a expansão e o dinamismo de um espaço geográfico qualquer se materializam, tornam-se visíveis, nas cidades (HARVEY, 2005).

Neste sentido, 
“...] é um espaço novo que foi constituído no século XX, em escala mundial; a sua produção, inacabada, continua. o novo modo de produção (a sociedade nova) se apropria, isto é, arranja para seus fins o espaço preexistente, modelado anteriormente. Modificações lentas, penetrando em uma espacialidade já consolidada, mas perturbando-a às vezes com brutalidade (caso dos campos e paisagens rurais no século XX) (LEFEBVRE, 2013, p. 128)."

As cidades são facilitadoras do acesso aos serviços e mercadorias e representam uma miríade de possibilidades que atraíram bilhões de moradores e desde a Revolução Industrial o grau de urbanização continua aumentando em praticamente todo o planeta.

A hierarquia do processo urbano é bem conhecida e o ritmo é ditado a partir do centro mais dinâmico do capitalismo, através da integração de áreas que oferecem perspectivas lucrativas, resultando em novas dinâmicas para os espaços eleitos, bem como, reafirmando o controle sobre áreas homogeneizadas pela consolidação do mercado e também mantendo outros tantos espaços quase que excluídos do processo econômico por não apresentarem nada de significativo para exploração.

De acordo com Corrêa (2000):

"O espaço urbano capitalista - fragmentado, articulado, reflexo, condicionante social, cheio de símbolos e campo de lutas - é um produto social, resultado de ações acumuladas através do tempo, e engendradas por agentes que produzem e consomem o espaço. A ação destes agentes é complexa, derivando da dinâmica de acumulação de capital, das necessidades mutáveis de reproducãa das relações de produção, e dos conflitos de classe que dela emergem. A complexidade da ação dos agentes sociais inclui práticas que levam a um constante processo de reorganização espacial que se faz via incorporação de novas áreas ao espaço urbano, densificação do uso do solo, deterioração de certas áreas, renovação urbana, relocação diferenciada da infra-estrutura e mudança, coercitiva ou não, do conteúdo social e econômico de determinadas áreas da cidade (Corrêa, 2000, p. 11)"
Neste aspecto, mesmo em cidades pequenas ${ }^{3}$, têm-se os espaços destinados às classes mais pobres e aqueles para a elite. Aliás, as áreas urbanas que recebem os maiores investimentos do Poder Público, quase sempre, coincidem com as propriedades dos mais ricos e, quando investimentos de grande monta são realizados nas áreas mais carentes, como obras viárias, acabam resultando no desalojamento dos mais pobres, seja através das desapropriações para realização das obras ou pelo aumento do custo de vida nas áreas beneficiadas.

De acordo com Barreto Filho e Marques (2016):

"O quadro [socioespacial das cidades] retrata e reproduz as injustiças e desigualdades da sociedade. A concentração de riquezas em uma parcela diminuta exclui e 'empurra' contingentes populacionais significativos para o entorno da cidade, quer sejam oriundos de áreas urbanas afetadas pela expansão (especulação) imobiliária ou proveniente da zona rural do próprio município ou de outros (BARRETO FILHO; MARQUES, 2016)."

Reconhecendo também a diferenciação econômica, aspecto inerente ao MPC, entre os agentes que "produzem e consomem" o espaço se compreende a heterogeneidade existente, inclusive nas cidades pequenas do Semiárido. Segundo Sposito (2010), as cidades apresentam tamanhos e funcionalidades diferentes, tendo em vista o processo histórico, a política, a economia, a geografia etc., que Ihes conferem identidades específicas, muito embora possam existir semelhanças.

Jurado da Silva e Sposito (2009) fazem uma discussão geográfica sobre o conceito de cidades pequenas e salientam que as "generalizações e simplificações" devem ser afastadas nas análises, devendo-se focar "suas especificidades e particularidades." Os autores sustentam que:

"[...] as cidades pequenas também apresentam importantes diferenciações entre si, e isso decorre da própria lógica instaurada historicamente pelo movimento 
da sociedade. Assim, as distinções podem variar tanto na escala demográfica e nas dinâmicas econômicas, quanto ao próprio papel político que esses centros exercem na divisão territorial do trabalho, etc. No entanto, tais distinções não impossibilitam que esses centros ainda sejam caracterizados como cidades pequenas, dado ao próprio aspecto qualitativo que os mesmos reúnem, ou seja, o de possibilitar o atendimento das "demandas inadiáveis da população' (JURADO DA SILVA; SPOSITO, 2009, p. 206)."

Pelo entendimento de Jurado da Silva e Sposito (2009), a característica geral da cidade pequena parece ser a capacidade de atender as demandas básicas da população, tais como alimentação, vestuário, além de serviços pessoais e coletivos que não exijam graus de sofisticação. Tentando esclarecer essa característica geral, os autores afirmam que:

"[...] as cidades pequenas oferecem o qualificativo inicial para a caracterização do urbano e da cidade porque, núcleos dessa magnitude, não apresentam dimensões populacionais muito complexas, o que permite avaliar com melhor clareza como se expressam as principais demandas da população."

Neste aspecto, os autores sugerem uma definição de urbano para além do componente políticoadministrativo e que contemple a capacidade de atendimento das demandas básicas da população. Tal perspectiva supera as questões eminentemente quantitativa dos tamanhos territorial e populacional como elementos determinantes para a definição de cidade pequena, também contemplando a:

"[...] articulação das escalas intra e interurbana, uma vez que o verdadeiro sentido de cidade tende a ser mais bem apreendido pelas relações em que a cidade estabelece, e não por uma análise neutra e descolada da realidade, isto é, deve-se levar em conta, sobretudo, sua situação geográfica" (JURADO DA SILVA; SPOSITO, 2009, p. 209)."

Ao se considerar a situação geográfica e as relações que a cidade estabelece, necessariamente, tem-se que analisar os papeis que exerce na rede urbana. Assim:

"[...] o espaço das pequenas cidades ganha qualificativos relevantes. Desse cenário, pode-se extrair a produção, 0 consumo, a circulação e os diversos fluxos que compõem a realidade urbana, bem como podemos apreciar a influência politico-econômica que uma determinada cidade exerce em relação as suas proximidades e/ou sua região. Então, compreendemos que a dimensão histórica da rede urbana tende a revelar a lógica dos papéis que uma determinada cidade assumiu e/ou assume temporalmente na dinâmica das relaçōes capitalistas de produção" (JURADO DA SILVA; SPOSITO, 2009, p. 209).

Em outros termos, pode dizer que as interrelações estabelecidas na rede urbana exercem papel central para se compreender os papeis desempenhados pelas cidades pequenas ${ }^{4}$. Ademais, não se pode perder de vista que são as forças orientadoras do sistema capitalista que, em última instância, definem os papeis e a hierarquia existente entre as cidades. Portanto, "as cidades pequenas, atualmente, emergem como resultado da própria divisão territorial e social do trabalho, articuladas no processo de um desenvolvimento desigual e combinado." (JURADO DA SILVA; SPOSITO, 2009, p. 210).

Ressaltando-se que operam, simultaneamente, para a (re)produção espacial: as determinações gerais do sistema capitalista (seu caráter expansível, a busca pelo lucro, centralização e concentração, as forças orientadoras do processo de acumulação) eas particularidades (apreendidas a partir da sondagem das heranças históricas diferenciadas), sendo que, determinam, dialeticamente, as estruturas, formas e funções dos diferentes espaços.

4 Conforme Barreto Filho e Lima Jr. (2021, p. 5): "As mudanças prováveis na hierarquização clássica entre as cidades, do Centro Local até a megalópole, são decorrentes da intensificação do processo de globalização. Isso por que não se pode perder de vista que os avanços tecnológicos das últimas décadas permitiram a interconexão dos espaços mais longínquos diretamente aos centros mais modernos, tornando cada vez mais complexas as relações existentes entre as cidades. A velocidade com que as mudanças ocorrem parece crescente e a (re)configuração espacial frente aos contextos internacional e nacional impõem novos desafios sobre os papeis que os diferentes tipos de cidades desempenham em benefício do MPC." 


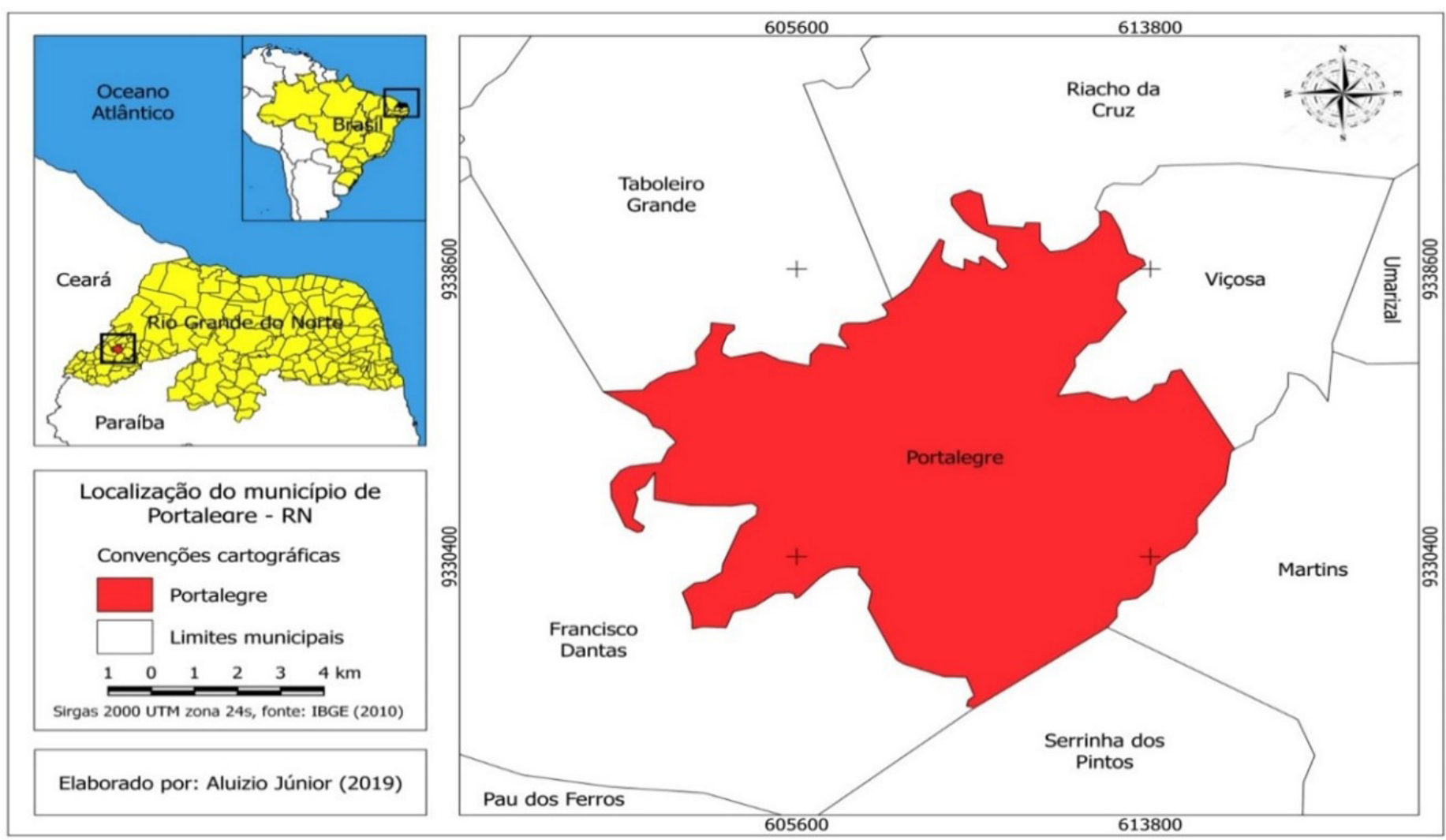

Fig. 1. Localização e limites geográficos do município de Portalegre/RN (FRANÇA; ESTEVAM; BARRETO FILHO, 2020), cartografia de Bezerra Junior (2019) a partir de Base Cartográfica do IBGE (2010).

\section{Portalegre/RN: breve caracterização}

Oficialmente, o município de Portalegre/RN está situado na porção central da Região Geográfica Imediata de Pau dos Ferros 5 (Figura 1).

De acordo com dados do Censo Demográfico de 2010, a população total alcançava 7.320 habitantes, dos quais 3.843 moravam na zona urbana e os outros 3.477 residiam na zona rural, apresentando uma taxa de urbanização de 52,50\%. A densidade demográfica do município era de $66,51 \mathrm{hab} . / \mathrm{km}^{2}$ em 2010, distante $33 \mathrm{~km}$ de Pau dos Ferros/RN (via RN 177), ocupando uma área de $82,69 \mathrm{~km}^{2}$, tendo os municípios de Viçosa/RN, Riacho da Cruz/ RN, Taboleiro Grande/RN, Francisco Dantas/RN, Serrinha dos Pintos/RN e Martins/RN como vizinho. O município apresentou taxa de crescimento populacional anual de 0,66\%, entre 1991 e 2000, e 0,82\% entre 2000 e 2010 (IBGE, 1991; 2000; 2010; 2017). A estimativa populacional para 2019 era de 7.867 habitantes (IBGE, 2020).

5 O IBGE passou a adotar, a partir de 2017, uma nova nomenclatura para a divisão regional. A região em que o município de Portalegre/RN está inserida também é conhecida como Alto Oeste Potiguar e "Tromba do elefante".
Em relação a rede urbana, verifica-se que 161 cidades do RN estão na área de influência de Natal/ RN. O Arranjo Populacional de Natal/RN (AP Natal/ $\mathrm{RN}$ ), conta com uma Capital Regional C (Mossoró/ $R N$ ); quatro Centros Sub-Regionais B (Açu/RN, Caicó/RN, Currais Novos/RN e Pau dos Ferros/RN; dois Centros de Zona A: João Câmara/RN e Santa Cruz/RN; oito Centros de Zona B: Angicos/RN, Antônio Martins/RN, Canguaretama/RN, Lajes/RN, Parelhas/RN, Patu/RN, São Miguel/RN e São Paulo do Potengi/RN e as demais cidades são classificadas como Centros Locais, pois exercem influência apenas nos seus próprios limites territoriais, como é o caso de Portalegre/RN (IBGE, 2020).

O município de Portalegre/RN tem sua base econômica muito dependente do Setor Público (servidores públicos e transferências diretas à população), apresenta um setor comercial e de serviços com a presença predominante de micro e pequenas empresas, sendo muito forte a presença de informais, dispõe de alguns poucos pontos turísticos que servem, prioritariamente, ao turista da região e uma agricultura em decadência, conforme dados apresentados na Tabela 1 e na Figura 2. 
Tabela 1. Produto Interno Bruto (PIB) Municipal, Valor Adicionado Bruto (VAB) total e por setores, Impostos Líquidos, a Preços Correntes, de Portalegre/RN (2010 a 2017) (xR\$1.000) (IBGE, 2020).

\begin{tabular}{ccccccccc}
\hline Item & $\mathbf{2 0 1 0}$ & $\mathbf{2 0 1 1}$ & $\mathbf{2 0 1 2}$ & $\mathbf{2 0 1 3}$ & $\mathbf{2 0 1 4}$ & $\mathbf{2 0 1 5}$ & $\mathbf{2 0 1 6}$ & $\mathbf{2 0 1 7}$ \\
\hline PIB & 36710 & 38948 & 43697 & 46087 & 47546 & 53193 & 53888 & 59752 \\
VAB & 35368 & 37427 & 42038 & 44540 & 45616 & 51314 & 52278 & 58152 \\
Agro & 1112 & 1583 & 982 & 1185 & 1826 & 1151 & 1033 & 1059 \\
Ind. & 5476 & 4061 & 5466 & 4945 & 4717 & 6259 & 5356 & 8417 \\
Serv. & 7194 & 7673 & 8558 & 9108 & 8802 & 10633 & 11661 & 12070 \\
Adm. Pub. & 21587 & 24109 & 27031 & 29302 & 30270 & 33270 & 34227 & 36605 \\
Imp. Líq. & 1342 & 1521 & 1660 & 1547 & 1930 & 1879 & 1609 & 1600 \\
\hline
\end{tabular}

Observa-se que a economia municipal é estruturalmente frágil, com participações modestas do Setor Agropecuário e da Indústria e com peso relativo mais expressivo da Administração Pública. Ademais, conforme evidenciado na Figura 2, o Setor Agropecuário vem mantendo uma participação muito pequena em toda a série. O Setor de Serviços mantem uma trajetória de gradativo crescimento, com a Administração Pública apresentando trajetória mais ascendente a partir de 2014 e a Indústria a partir de 2016.

A zona rural de Portalegre tem a cajucultura como principal atividade produtiva, mas as evidências indicam que as famílias residentes nos minifúndios se dedicam a variadas atividades, muitas delas não agrícolas, destacando-se a presença de muitos aposentados e pensionistas nas famílias. A agropecuária do município de Portalegre/RN, ainda que muito modesta, está fundamentada no

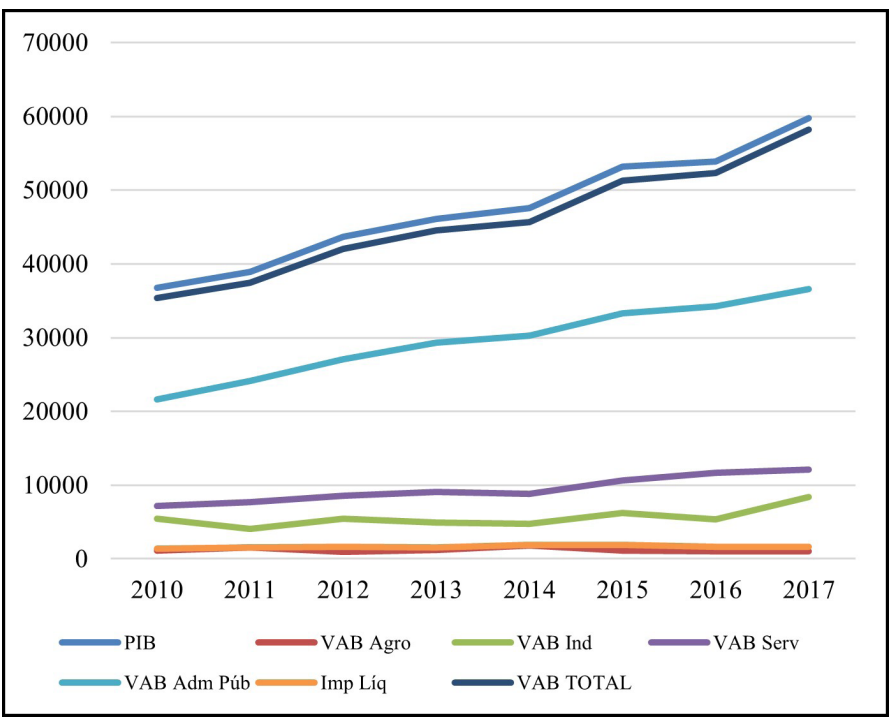

Fig. 2. Evolução Produto Interno Bruto (PIB) Municipal, Valor Adicionado Bruto (VAB) total e por setores, Impostos Líquidos, a Preços Correntes, de Portalegre/RN (2010 a 2017) (IBGE, 2020). cultivo de algumas lavouras permanentes, com destaque para a cajucultura e umas poucas culturas temporárias, como a mandioca, o milho, a cana-deaçúcar e o feijão.

A geração de receita própria é limitada em cidades pequenas, agravando-se o quadro em virtude da recessão econômica, com reflexos evidentes nas transferências intergovernamentais vivenciada nos últimos anos, sendo também afetada pela seca de 2012 a 2017 e a consequente redução da produção agropecuária.

Em linhas gerais, pode-se afirmar que a característica marcante das economias nos municípios potiguares com menos de 10 mil habitantes, como é o caso de Portalegre/RN, é a proeminência do setor de serviços, com destaque para a participação do Setor Público no PIB, compatibilizando-se com a análise de Gomes (2001) sobre a existência de municípios "sem produção" no Semiárido.

Em relação a regulamentação de uso e ocupação do solo urbano, apurou-se que o município não dispõe de Plano Diretor, fazendo uso das normas previstas no Código de Posturas (Lei Complementar $N^{0}$. 007/2017, de 30 de maio de 2017) e do Código Sanitário, também de 2017.

\subsection{Análise da produção do espaço de Por- talegre/RN}

A Figura 3 mostra as áreas de expansão da cidade de Portalegre/RN, considerando o plano morfológico. O Centro Histórico segue o padrão português de constituição de povoados, com a Igreja, a Praça Central, o Mercado, o antigo prédio 


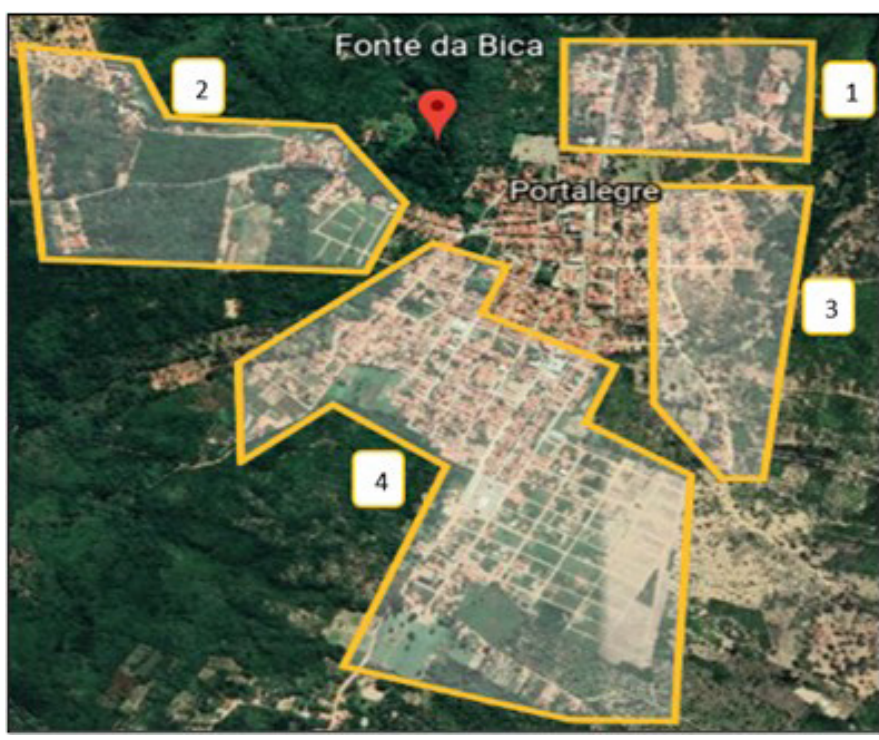

Fig. 3. Visão geral da cidade de Portalegre/RN com áreas de expansão (Google Earth Pro, 2021).

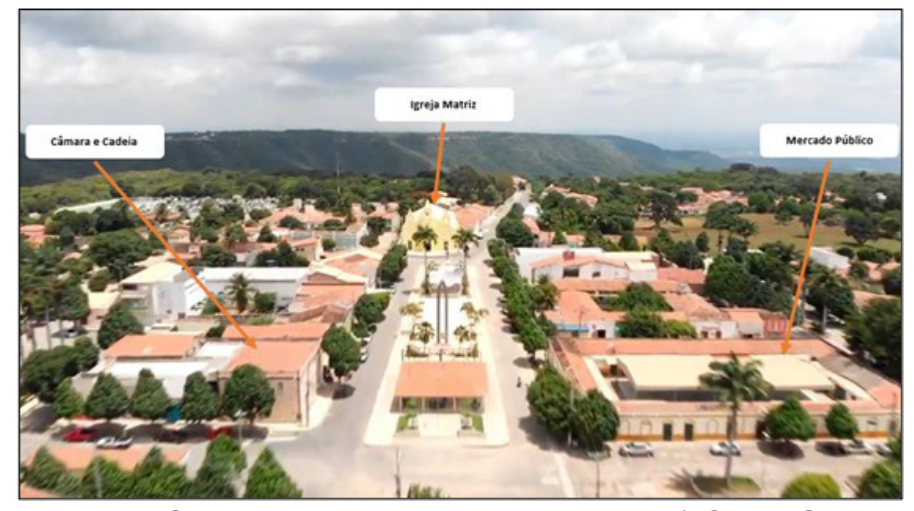

Fig. 4. Centro da cidade de Portalegre/RN (KOBAYASHI, 2020).

em que funcionava a Câmara e a Cadeia, uma escola e o entorno em que foram erguidas as primeiras casas. Ao longo do tempo as construções foram erguidas a partir da área central, porém com expansão muito tímida, em conformidade com as demais pequenas cidades que integram o Alto Oeste Potiguar.

Observa-se no espaço do quarteirão central as duas construções mais antigas da cidade, destacando-se a Igreja, uma vez que os proprietários que implantavam as sedes das fazendas, geralmente, providenciavam a construção de uma capela, e o prédio de Câmara e Cadeia, local de funcionamento da administração do povoado criado no século XVIII (Figura 4).

Também na Figura 4, se observa o Mercado Público, espaço da antiga feira semanal e dos pequenos estabelecimentos comerciais que foram sendo erguidos, provavelmente, a partir do século
XIX e que recebeu a cobertura da área central no início do século XX, sendo substituída pela atual estrutura metálica no início da década de 1980.

Atualmente, percebe-se certo adensamento de estabelecimentos comerciais no entorno da Praça Central e ruas adjacentes, concentrando mercadinhos, farmácias, lotérica, óticas, lojas de vestuário, materiais de construção, bares, etc. Assim, a área central, obviamente dotada com a infraestrutura básica provida pelo Poder Público e que concentra órgãos públicos, como escolas, unidades de saúde, centro administrativo, espaço cultural, dentre outros, alcançou maior valorização imobiliária, constituindo-se em vantagem econômica para os proprietários dos imóveis em tal área da cidade.

Algumas áreas de expansão identificadas na Figura 3 também resultaram de estímulos provenientes do Poder Público. As áreas 1 e 2 tiveram acentuada valorização econômica em virtude da instalação de equipamentos turísticos a partir do final da década de 1990. A área 1 recebeu o principal equipamento turístico existente na cidade. Trata-se de um empreendimento privado, mas que recebeu incentivos fiscais (isenção de impostos municipais por vinte e cinco anos) e benefícios oferecidos pela gestão municipal, como a doação do terreno, a pavimentação do acesso e expansão das redes de água e energia até o empreendimento. O resultado foi a valorização significativa dos terrenos nas proximidades e na via de acesso ao hotel, com vantagens econômicas mais acentuadas para alguns proprietários dos maiores terrenos.

A área 2 foi contemplada com a construção de um mirante ${ }^{6}$, através de recursos captados junto ao Governo Federal, atraindo em sequência o interesse de investidores privados, com a construção de uma pousada em frente e, posteriormente, um restaurante e mais uma pousada nas cercanias do mirante público. A gestão municipal também construiu uma praça e pavimentou o acesso ao local. A implantação dos equipamentos turísticos na área

6 Até o início de 2018, o equipamento permaneceu fechado, aguardando realização de licitação para ocupação do estabelecimento. Ressalte-se que foi realizada uma reforma, novamente com realização de convênio com o Governo Federal. 


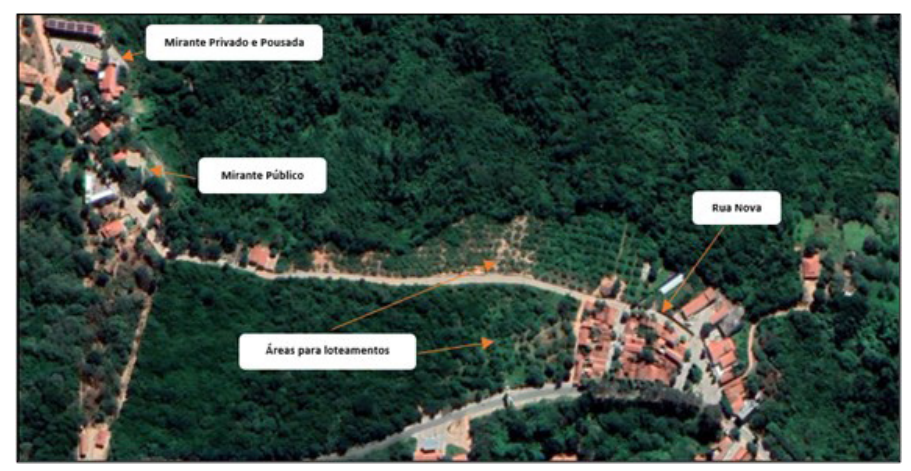

Fig. 5. Área de expansão 2 com destaque para o conjunto "Rua Nova", área de loteamentos e equipamentos turísticos Portalegre/RN (Google Earth Pro, 2021).

2 também resultou na valorização dos terrenos, inclusive com a implantação de loteamentos.

Antes da construção do mirante público a área era destinada a exploração agrícola, com destaque para a cajucultura, composta de estabelecimentos da agricultura familiar. A instalação do equipamento turístico despertou o interesse de visitantes para a aquisição de lotes nas cercanias e para atendimento da demanda algumas áreas foram desmatadas para implantação de loteamentos, com significativa valorização de glebas de terras nos arredores do equipamento público (Figura 5), corroborando o argumento de Amaral (2009), de que a penetração do capital promove alterações espaciais, inclusive modificando o sistema de propriedade agrícola.

Apurou-se que alguns lotes $(20 \mathrm{~m} \times 30 \mathrm{~m})$, mais próximos aos declives e com visão panorâmica privilegiada do sertão, foram vendidos por R\$ 75 mil, enquanto que nos lotes $(10 \mathrm{~m} \times 20 \mathrm{~m})$ mais próximos a RN 177 os preços variam entre R\$ 15 mil e R\$ 25 mil. Destaque-se que nos anos anteriores à intensificação da crise econômica (até 2015) os preços eram ainda mais exuberantes, estimulandose ainda mais a especulação imobiliária.

No início da bifurcação que dá acesso ao equipamento turístico (Mirante Bela Vista), temse um aglomerado de moradias denominado "Rua Nova", reconhecido historicamente como um local de pessoas muito pobres, com predominância de negros.

Apurou-se que até a década de 1990, boa parte das casas era de taipa e sem acesso a infraestrutura básica, ademais, os moradores conviviam com as instalações precárias do Matadouro Público ao lado das casas. Considerando tais circunstâncias adversas vivenciadas pelos moradores da "Rua Nova", tem-se que a expansão turística mudou drasticamente a paisagem: as casas de taipa foram substituídas por casas de alvenaria (algumas casas foram substituídas antes da implantação dos equipamentos turísticos), as ruas foram pavimentadas, uma pequena praça foi construída, - Matadouro foi desativado, enfim, o aglomerado de casas de taipa se tornou uma área "organizada" (Figura 5).

Esse processo de "organizar" os espaços urbanos ocupados pelas classes sociais mais vulneráveis quando passam a despertar interesse econômico vem ocorrendo na pequena cidade de Portalegre/ RN, sendo mais evidente na "Rua Nova", em que as antigas e precárias moradias foram derrubadas e, cada vez mais, verifica-se a presença de atividades comerciais na área.

Alguns aspectos ainda merecem a devida atenção das autoridades municipais, destacandose a provável pressão econômica para que os moradores vendam suas casas, tendo em conta a perspectiva da comunidade constituída de pobres e negros ficar espremida por loteamentos destinados às classes de maior poder aquisitivo, aliás, apurouse que algumas falas denotam um claro viés preconceituoso em relação aos moradores mais antigos.

Um segundo ponto, no trabalho de campo, também chamou à atenção. Apurou-se que tratores pertencentes à Prefeitura abriram uma estrada em direção a Fonte da Bica (ponto turístico em que uma fonte jorra água permanentemente e que ainda dispõe de algumas árvores típicas da Mata Atlântica), restando possível algum tipo de impacto ambiental em função da remoção da cobertura vegetal nas proximidades da nascente. Salientese ainda que, segundo Medeiros et al (2018), - Poder Público municipal instituiu, através do Decreto Municipal 002/2016, a Área de Relevante Interesse Ecológico Econômico (ARIE) Mata da Bica, deixando evidente que, diante de interesses privados, a exploração econômica é colocada a frente da preservação ambiental.

A área 3 é de expansão recente, pós ano 2000, 


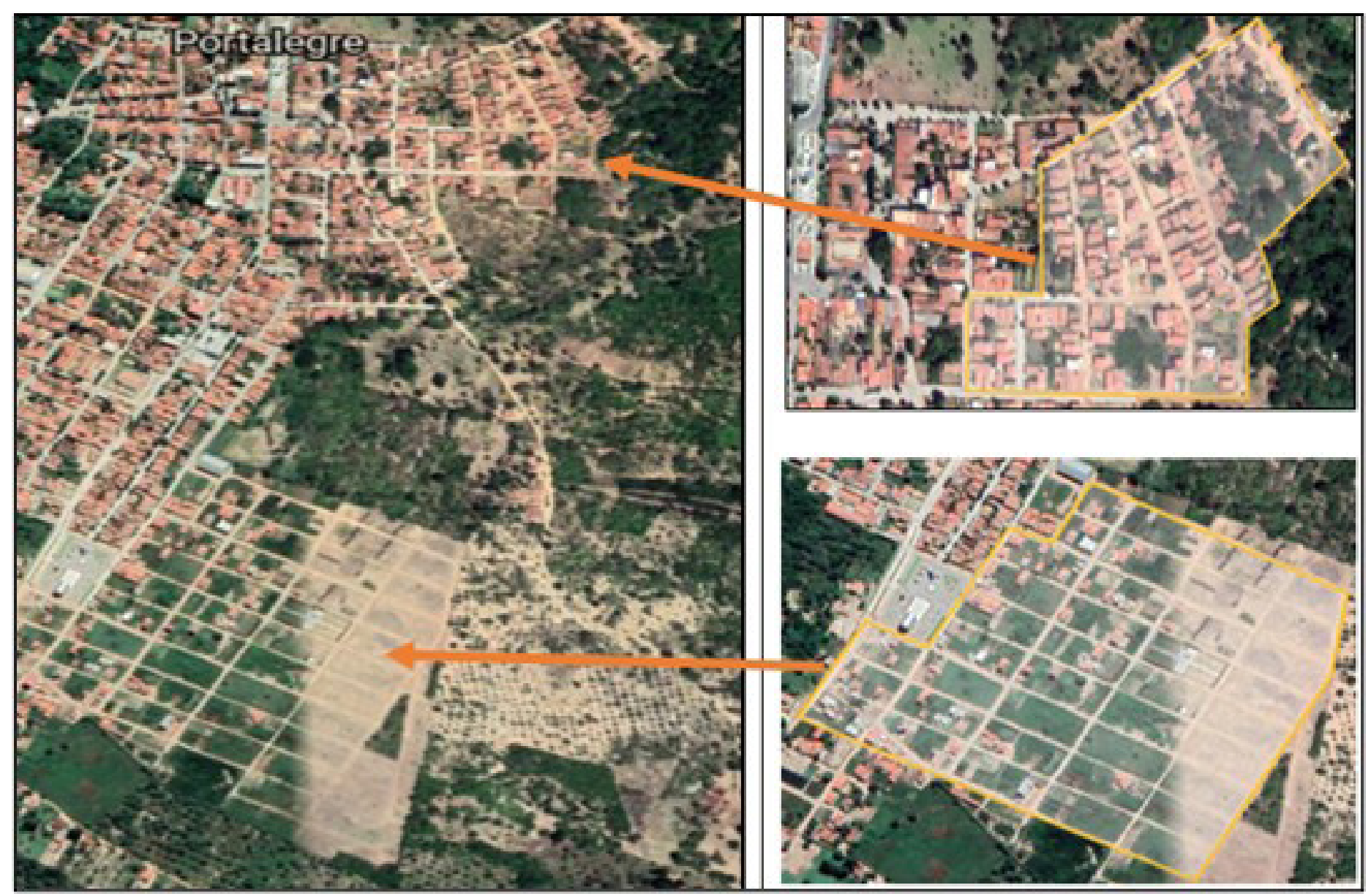

Fig. 6. Área de expansão 3 com destaque para os novos loteamentos - Portalegre/RN (Google Earth Pro, 2021).

puxada pela implantação de loteamentos (Figura 3 e 6). Verificam-se algumas ruas sem pavimentação e iluminação deficitária nas áreas de implantação de loteamentos.

A partir do centro da cidade (Mercado Público) ocorreu uma acentuada expansão para o Leste, com inúmeras construções sendo erguidas no prolongamento da Rua Manoel de Freitas (em direção ao sítio São Bento) e Rua Antônio Alvino de Souza (em direção ao sítio Pelo Sinal), com áreas até então destinadas para a exploração agropecuária e que foram (continuam sendo) loteadas. Tal movimento resultou na abertura de várias ruas, como a Rua Euclides Luiz Pereira.

Vale ressaltar também uma mudança no perfil de parte das novas construções, com casas recuadas e muitas delas com um andar superior, diferenciando-se do padrão das residências mais antigas com janelas e portas dando acesso direto as vias públicas, separadas apenas por uma calçada de cerca de dois metros de largura. Além do aspecto associado à modernidade, apurou- se que elementos como privacidade e segurança também foram considerados para o isolamento das residências (construídas no centro dos lotes, com muros altos e cercas elétricas em algumas). A observação realizada durante a pesquisa de campo sugere uma tendência em tal caracterização das residências, mas ainda é bastante significativa a presença de moradias mais modestas, sem muros de isolamento.

A mudança funcional pode ser percebida através da remoção de algumas atividades realizadas no Perímetro Urbano até o início da década de 1990 e que, certamente, em tempos atuais, não são mais toleradas. Na pesquisa de campo e nas entrevistas realizadas foi possível levantar que, no início da Rua Antônio A. de Souza (partindo do Centro), funcionou - Açougue Municipal, em que os comerciantes expunham as carnes em bancas de alvenaria e penduradas em ganchos, sendo manuseadas por clientes, expostas ao contato de insetos e sem refrigeração, resultando num ambiente insalubre e com forte propagação de odores desagradáveis. 


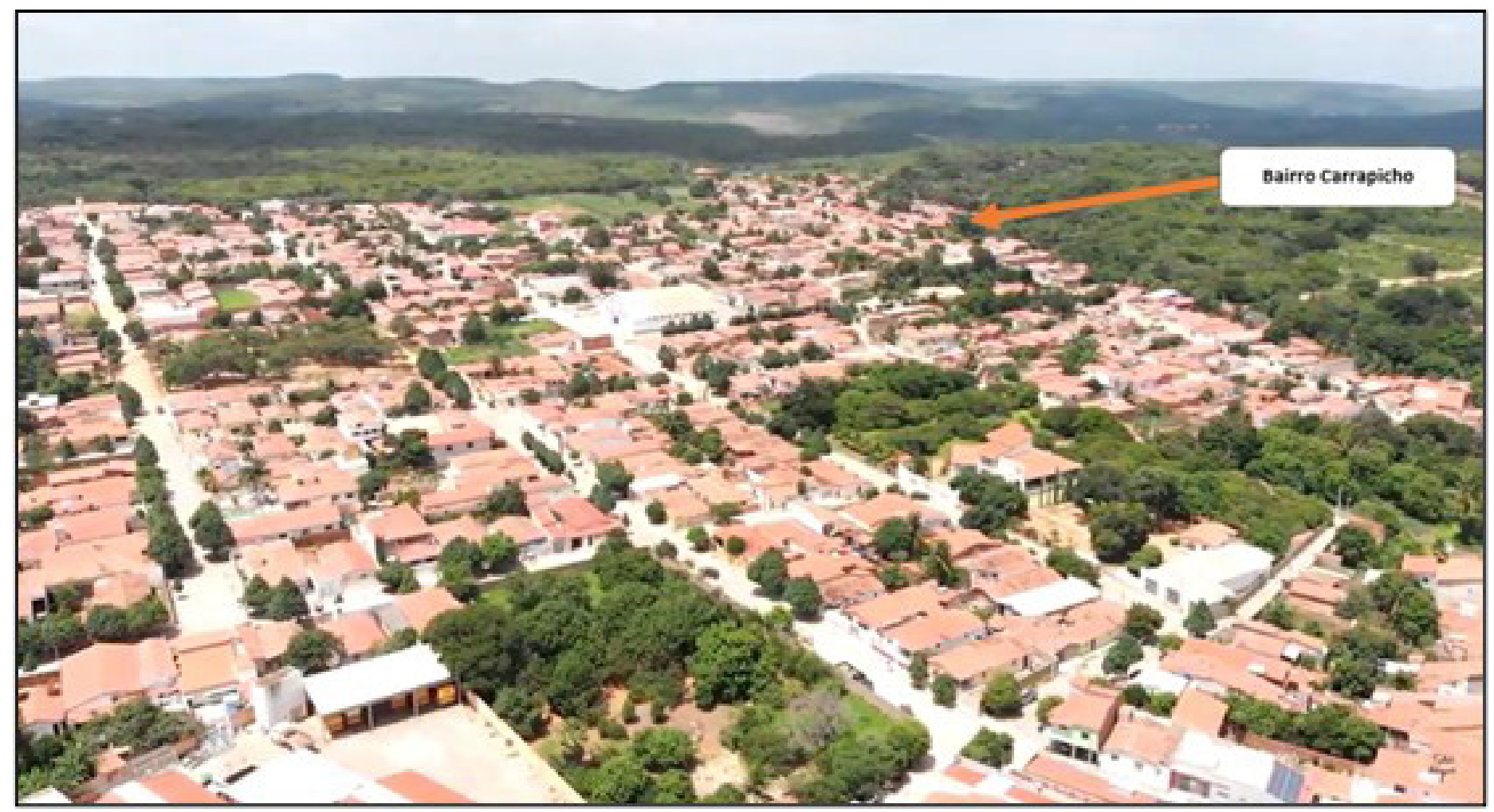

Fig. 7. Área de expansão 4 com destaque para o bairro Carrapicho - Portalegre/RN (KOBAYASHI, 2020).

Na mesma via, mais acima (partindo do Centro), existiu uma "Casa de Farinha", cujo período de safras resultava em intensa movimentação, inclusive de animais transportando a mandioca para o processamento, incompatibilizando-se, especialmente pelo barulho de equipamentos e pessoas (inclusive durante o período noturno), com uma área de maior adensamento residencial. Assim, a expansão através dos loteamentos eliminou atividades econômicas tradicionais executadas, indevidamente, na zona urbana.

A área 4 apresenta algumas particularidades (Figura 3). A primeira se refere a construção do conjunto da Companhia de Habitação Popular do RN (COHAB) na década de 1980, constituindo-se na primeira expansão planejada da cidade. O conjunto, constituído por três ruas, puxou o crescimento para o Sul e o primeiro loteamento lançado por uma empresa especializada, após o conjunto da COHAB, confirma a tendência de expansão organizada em tal área, aliás, no referido loteamento, planeja-se a implantação do primeiro condomínio fechado da cidade.

É interessante observar que o Conjunto da COHAB foi implantado por uma empresa estatal, com nítido viés social, enquanto que o loteamento é resultado da ação empreendedora privada, orientada pela expansão do crédito para financiamento de moradias e pelo crescimento da demanda de imóveis, principalmente terrenos, nas cidades serranas do Alto Oeste Potiguar, com destaques para Martins/RN e Portalegre/RN.

A segunda particularidade urbanística é que a área 4 conta com um Conjunto Popular, denominado "Carrapicho", que resultou da construção de moradias distribuídas a população de baixa renda, pós ano 2000, pelo Poder Público (Figura 7).

As casas populares foram construídas num terreno que foi adquirido pela Poder Público municipal e que até então era explorado como estabelecimento rural, percebendo-se em tal movimento certo viés de segregação socioespacial, tendo em vista que a área não dispunha de quaisquer equipamentos públicos e de infraestrutura na época em que as casas foram construídas.

De acordo com Lima et. al., (2017, p. 257), foi realizado um levantamento preliminar no Conjunto "Carrapicho", com o propósito de buscar a regularização fundiária dos lotes, identificando-se 83 unidades, mas que o trabalho não foi possível 
"[...] devido à inviabilidade jurídico-fundiária [...]". Depreendendo-se que a construção das casas e distribuição realizadas pelo Poder Público não contemplou a titulação dos imóveis para os beneficiários, restando plausível que a Prefeitura mantem a posse dos terrenos.

O espaço é um produto social e econômico e as mudanças, relativamente recentes, perceptíveis em Portalegre/RN decorreram da estruturação de equipamentos turísticos construídos e/ou incentivados pelo Poder Público, pela disposição de alguns proprietários de áreas nos arredores da cidade em loteá-las e pela construção de bairros populares nas franjas da cidade.

Assim, pode-se sistematizar os principais resultados da pesquisa nos seguintes aspectos:

1) O fator decisivo de expansão na área 1 foi a decisão do Poder Público municipal oferecer benefícios fiscais (isenção de impostos municipais por 25 anos) e atrativos (doação de terreno, pavimentação de acesso, rede de distribuição de água, energia elétrica) para um empresário do ramo hoteleiro. Observa-se a assimilação de recursos públicos pelo capital, justificando-se tal movimento pela importância do empreendimento para a geração de emprego e renda para os portalegrenses e pelos rebatimentos econômicos provenientes da estruturação do setor turístico no município.

Em tal circunstância a produção do espaço contou com o Poder Público municipal como agente fomentador e o capital como beneficiário imediato, com desdobramentos, num segundo momento, para a valorização de terrenos, especialmente de uns poucos proprietários que dispõem de áreas não construídas maiores nas cercanias do hotel.

2) A mesma lógica de produção do espaço ocorreu na área de expansão 2. Deu-se pela implantação de um equipamento turístico (mirante), numa área até então destinada à atividade agrícola, com destaque para a cajucultura, realizada em estabelecimentos da agricultura familiar.

A estrutura turística (mirante) foi repassada para exploração privada e a área do entorno despertou o interesse de alguns empresários (duas pousadas e um restaurante foram construídos), também ocorreu a implantação de loteamentos, com significativa valorização das terras, configurandose numa área de especulação imobiliária. Tais movimentos permitiram, num primeiro momento, a melhoria das condições de habitabilidade da população da "Rua Nova", comunidade com forte presença de negros e pobres, entretanto, a configuração espacial em andamento sugere uma pressão econômica crescente sobre os moradores remanescentes, uma vez que as casas estão cercadas por áreas de loteamentos destinados às classes com maior poder aquisitivo.

Sabe-se que a disponibilidade de força de trabalho abundante contribui para o êxito dos empreendimentos privados, mas também é inegável que as áreas valorizadas não são destinadas à moradia dos pobres. Assim, a produção do espaço proveniente da expansão do turismo, com a valorização decorrente da oferta de infraestrutura implantada pelo Poder Público, tende a expulsar os mais pobres de tais espaços.

À medida que os espaços são valorizados pelo adensamento de empreendimentos privados (estabelecimentos comerciais e loteamentos), observam-se ações mais vigorosas do Poder Público, dotando-se tais áreas com mais equipamentos e infraestrutura, cujas rodadas sucessivas de investimentos privados e públicos, na escala de uma cidade pequena do Semiárido, reproduzem os movimentos de separação socioespacial de ricos e pobres que se verifica com relativa facilidade nas cidades médias e grandes, além de deixar evidente que o espaço intervém na sua própria produção, conforme apontado por Lefebvre (2013).

3) A produção do espaço na área 3 não foi resultado da implantação de equipamentos turísticos, tampouco conta com a mesma disponibilidade de intervenções realizadas pelo Poder Público, muitas ruas ainda não receberam pavimentação, nem foi localizada a implantação de nenhum equipamento público (praça, escola, etc.). Apurou-se que a expansão decorreu de iniciativas dos proprietários de algumas áreas em loteá-las.

4) A área 4 conta com a primeira experiência de expansão planejada da cidade, através da 
construção do conjunto da COHAB. As casas construídas pela companhia estatal de habitação foram distribuídas em 3 ruas e foi o estímulo para orientar o crescimento da cidade para o lado sul.

A partir dos anos 1990, ocorreu um movimento autônomo ${ }^{7}$ de expansão, com a constituição do Bairro "São José", em que inúmeras residências foram sendo construídas ao longo dos anos. Podese considerar que o primeiro movimento para a constituição do Bairro "São José" foi a construção de um clube social para realização de festas ainda na década de 1980, depois a gestão municipal passou a realizar algumas intervenções, destacando-se a construção de um Ginásio Esportivo (década de 1990) e, mais recentemente, uma Creche Modelo (pós ano de 2010).

Outra intervenção pública realizada na área de expansão 4 foi a construção de casas destinadas a população de baixa renda. Pode-se afirmar que a experiência segue o padrão de destinação de áreas afastadas do centro e sem infraestrutura mínima para as populações pobres, com nítido viés de segregação socioespacial. Este aspecto se torna mais evidente quando se observa que inúmeros terrenos sem construções são mantidos nas áreas centrais, com disponibilidade de infraestrutura, mas que foram (são) preservados pelo Poder Público para não confrontar interesses privados, destinando-se apenas para a valorização imobiliária.

\section{Considerações finais}

A pesquisa buscou analisar a produção do espaço na cidade de Portalegre/RN, mesmo se tratando de uma cidade pequena no Semiárido restou evidenciado que existem elementos compatíveis com aqueles observados em cidades de grande porte, destacando-se, no caso estudado, as intervenções do Poder Público como agente do processo, comatuação direta através da implantação de equipamentos públicos e, indiretamente, pela expansão do perímetro urbano para contemplar a incorporação de glebas rurais à zona urbana.

Afirma-se que a produção do espaço na

7 Termo utilizado para diferenciar dos movimentos impulsados, deliberadamente, pelo Poder Público. cidade de Portalegre/RN tem forte presença do Estado, destacando-se as ações voltadas para a implantação de equipamentos turísticos. Neste sentido, o impulso para a expansão decorreu dos atrativos turísticos que a cidade serrana apresenta, como um clima mais ameno em relação ao entorno, cachoeiras, trilhas ecológicas, sítios arqueológicos e com formações rochosas atrativas etc. e que passaram a ser explorados pela ação do Poder Público como um diferencial econômico. (FERNANDES, SOUZA; DANTAS, 2010).

Evidentemente, sabe-se que o turismo, além de empregos e renda, também pode gerar resultados deletérios: especulação imobiliária, crescimento de atividades ilícitas (drogas e prostituição), mudanças culturais (o choque de hábitos culturais diferenciados entre moradores e visitantes), a orientação, às vezes, excessiva para agradar os visitantes e turistas, a priorização na localização dos investimentos para atender determinados grupos em detrimento de investimentos socialmente mais justos, pressões demasiadas sobre o meio ambiente, como evidenciado pelo avanço de loteamentos e construções de moradias e empreendimentos comerciais sobre a ARIE Mata da Bica.

Outra circunstância que deve merecer atenção por parte das autoridades é a necessidade em aprimorar os instrumentos de uso e ocupação do solo urbano, especialmente a elaboração do Plano Diretor, devendo considerar as distintas demandas sociais e não apenas os interesses de uns poucos que atuam como agentes da especulação imobiliária. Não se desconhece o interesse de classe assumido pelo Estado, mas se faz necessário não negligenciar as demandas provenientes dos segmentos sociais mais vulneráveis e daqueles que se preocupam com os impactos adversos sobre o meio ambiente.

Neste sentido, acredita-se que a atuação do Poder Público municipal possa se orientar pelas premissas do desenvolvimento sustentável, tratando de conciliar a preservação ambiental (até por que se constitui num diferencial e serve como atrativo turístico), as justas demandas dos estratos sociais mais vulneráveis e a necessidade de crescimento econômico. 


\section{Referências}

ALVES, G. A. A produção do espaço a partir da tríade lefebvriana concebido/percebido/vivido. Geousp - Espaço e Tempo (Online), v. 23, n. 3, p. 551-563, 2019.

AMARAL, F. O. M. (2009). Especulação imobiliária e segregação social em Palmas do Tocantins: uma análise a partir dos programas habitacionais no período de 2000 a 2008. 2009. 117 f. Dissertação (Mestrado em Arquitetura e Urbanismo) Universidade de Brasília, Brasília, 2009.

BALDIN, N.; MUNHOZ, E. M. B. Educação ambiental comunitária: uma experiência com a técnica de pesquisa snowball (bola de neve). REMEA - Revista Eletrônica Do Mestrado Em Educação Ambiental, v. 27, p. 46-60, 2012.

BARRETO FILHO, B. F.; LIMA JÚNIOR, F. Ó. Papel dos polos sub-regionais no processo de acumulação capitalista a partir da divisão espacial e hierarquia urbana no Rio Grande do Norte. Revista Geotemas, v.11, e02108, 2021.

BARRETO FILHO, B. F; MARQUES, E. S. Segregação socioespacial no município de Pau dos Ferros/ RN: "Conjunto Manoel Deodato e Beira-Rio". In: I Encontro Nacional de Planejamento UrbanoRegional no Semiárido (ENAPUR-SEMIÁRIDO). Anais... Pau dos Ferros (RN): UERN, 2016.

CARLOS, A. F. A. O Espaço Urbano: Novos Escritos sobre a Cidade. São Paulo: FFLCH, 2007.

CORRÊA, R. L. 0 espaço urbano. 4a ed. São Paulo: Ática, 2000.

DENZIN, N. K.; HAGUETTE, T. M. F. Metodologias qualitativas na sociologia. Petrópolis: Vozes, 1987.

FERNANDES, M. F. D.; SOUZA, R. C.; DANTAS, J. R. Q. O papel do Estado e das Políticas Públicas na definição do espaço turístico: um estudo de caso do município de Portalegre-RN. Revista de Políticas Públicas, v. 14, n. 1, p. 183-192, 2010.
FRANÇA, A. A.; ESTEVAM, S. M.; BARRETO FILHO, B. F. Microempreendedorismo e desenvolvimento local em Portalegre/RN: panorama atual. Revista Cadernos de Ciências Sociais Aplicadas, Ano XVII, v. 17, n 29, p. 88-105, 2020.

FRESCA, T. M. Centros locais e pequenas cidades: diferenças necessárias. Mercator-Revista de Geografia da UFC, v. 9, n. 20, p. 75-81, 2010.

GOMES, G. M. Velhas secas em novos sertões. Brasília: IPEA, 2001.

HARVEY, D. A produção capitalista do espaço. São Paulo: Anna Blume, 2005.

HARVEY, D. Cidades rebeldes: do direito à cidade à revolução urbana. São Paulo: Martins Fontes, 2014.

IBGE. Canais cidades@: Rio Grande do Norte, Portalegre. 2017. Disponível em http://www.ibge. gov.br/cidades (acesso em 28 de outubro de 2017).

IBGE. Sinopse do Censo 2010. 2010. Disponível em https://censo2010.ibge.gov.br/sinopse/ (acesso em 28 de outubro de 2017).

IBGE. Síntese de informações de municípios do Rio Grande do Norte. 2017. Disponível em http://cidades.ibge.gov.br/xtras/ uf.php? lang $=\&$ coduf $=24 \&$ search=rio-grande-donorte (acesso em 12 de outubro de 2017).

IBGE. Canais cidades@: Rio Grande do Norte, Portalegre, Panorama. 2020. Disponível em https://cidades.ibge.gov.br/brasil/rn/portalegre/ panorama (acesso em 8 de maio de 2020).

IBGE. Censos Demográficos. Portalegre/RN. Vários anos. Disponível em https://www.ibge.gov. br/estatisticas/sociais/populacao/9662-censodemografico-2010.html (acesso em 19 de maio de 2020).

IBGE. Regiões de influência das cidades: 2018. Coordenação de Geografia / IBGE. - Rio de Janeiro: 
IBGE, 2020.

JURADO DA SILVA, P. F.; SPOSITO, E. S. Discussão geográfica sobre cidades pequenas. GEOGRAFIA, Rio Claro, v. 34, n. 2, p. 203-217, 2009.

KOBAYASHI, T. Portalegre/RN: Imagens Aéreas. 2020. Disponível em https://www.youtube.com/ watch?v=IG617fed80w (acesso em 14 de agosto de 2021).

LEFEBVRE, H. Prefácio: a produção do espaço. Estudos avançados, v. 27, n. 79, p. 123-132, 2013.

LIMA, D. F. et al. Ordenamento territorial em foco: discutindo o programa acesso à terra urbanizada. Revista Estudo \& Debate, v. 24, n. 2, p. 249-267, 2017.

MEDEIROS, S. R. M. et al. Uso público da Área de Relevante Interesse Ecológico Mata da Bica/ Portalegre (RN): potencialidades e limitações. Revista Brasileira de Ecoturismo (RBEcotur), v. 11, n. 2, p. 221-249, 2018.

SPOSITO, E. S. A vida nas cidades. $5^{a}$ ed., $2^{a}$ reimpressão, São Paulo: Contexto, 2010.

TRIVIÑOS, A. N. S. Introdução à pesquisa em ciências sociais: a pesquisa qualitativa em educação. São Paulo: Atlas, 1987.

YIN, R. K. Estudo de caso: planejamento e métodos. Porto Alegre: Bookman, 2001. 